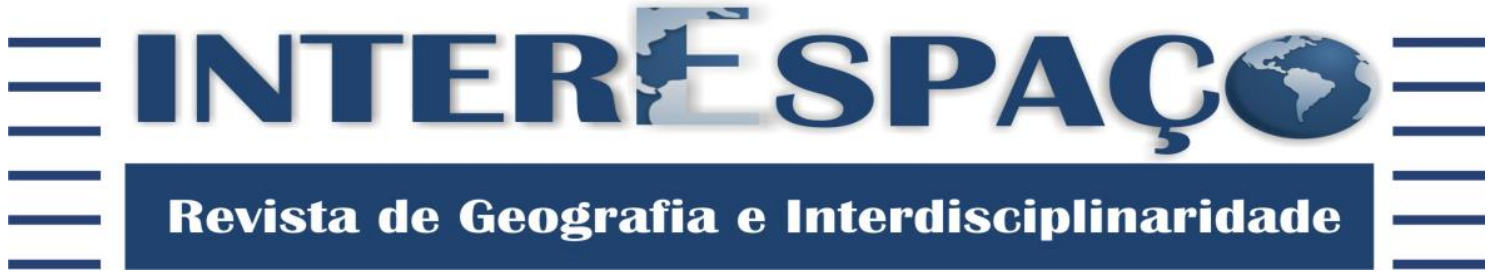

\section{PERIODIZAÇÃO E EVOLUÇÃO DA LOGÍSTICA URBANA DE CARGAS}

\author{
PERIODIZATION AND EVOLUTION OF URBAN LOGISTICS OF LOADS
}

PERIODIZACIÓN Y EVOLUCIÓN DE LA LOGÍSTICA URBANA DE CARGAS

\author{
Fander de Oliveira Silva \\ Doutorando e Mestre em Geografia pela Universidade Federal de Uberlândia - UFU. \\ fanderoliveira@ufu.br
}

\section{William Rodrigues Ferreira}

Doutor em Geografia Humana pela Universidade de São Paulo - USP. Professor do Instituto de Geografia e do Programa de Pós-graduação em Geografia da Universidade Federal de Uberlândia UFU.

wferreira@ufu.br

Recebido para avaliação em 25/01/2017; Aprovado para publicação em 11/04/2017.

\section{RESUMO}

A Logística tem apresentado uma contínua evolução no espaço urbano e no seu conceito funcional. Ao longo do seu desenvolvimento chegou a ser considerada um dos principais pontos estratégicos do sistema de produção integrado, incorporando inovações e gerando outras de acordo com o atual conceito de Gerenciamento de Cadeia de Suprimentos. O objetivo principal deste trabalho leva a compreender como a Logística Urbana se desenvolve no Brasil, que apesar de ter emergido tardiamente no país, em comparação com outros países, desenvolveu uma estrutura capaz de alimentar os circuitos espaciais produtivos e, além disso, se tornou um elemento importante no reordenamento do território brasileiro, ocupando posições de destaque na composição dos orçamentos públicos e privados.

Palavras-chave: Logística; Carga Urbana; Geografia dos Transportes.

\section{ABSTRACT}

Logistics, understood as transportation and storage of products, has presented a continuous evolution in the urban morphology and its functional concept. Throughout its development, it has been considered, together with Marketing, one of the main strategic points of the integrated production system, incorporating innoyations and generating others according to the current concept of Supply Chain Management (SCM). The main objective of this work is to understand how Logistics develops in Brazil, which, despite having emerged late in the country, compared to other countries, developed a structure capable of feeding the productive space circuits and, moreover, became an element Important in the reordering of Brazilian territory, occupying prominent positions in the composition of public and private budgets.

Keywords: Logistics; Urban Load; Geography of Transport.

\section{RESUMEN}

La Logística ha tenido una evolución continua en el espacio urbano y no su concepto funcional. A lo largo de su desarrollo llegó a ser considerada una de los principales puntos estratégicos del sistema de producción integrada, que incorpora innovaciones y genera otras en relación con el 
concepto actual de Gestión de la Cadena de Suministro. El objetivo principal de este trabajo lleva a entender la forma en que la logística urbana se desarrolla en Brasil, que a pesar de haber surgido tarde, en comparación con otros países, ha desarrollado una estructura capaz de alimentar los circuitos espaciales productivos y, por otra parte, se ha convertido en un elemento importante en la reorganización del territorio brasileño, ocupando posiciones destacadas en la composición de los presupuestos públicos y privados.

Palabras clave: Logística; Carga Urbana; Geografia dos Transportes.

\section{INTRODUÇÃO}

O movimento de pessoas, bens e informações sempre foi um componente fundamental da sociedade, sobretudo no período atual da história, caracterizado pela convergência técnica, científica e informacional e marcado pela força de grandes corporações.

O objetivo principal deste trabalho leva a compreender como a Logística Urbana se desenvolve no Brasil, que apesar de ter emergido tardiamente no país, em comparação com outros países, desenvolveu uma estrutura capaz de alimentar os circuitos espaciais produtivos e, além disso, se tornou um elemento importante no reordenamento do território brasileiro, ocupando posições de destaque na composição dos orçamentos públicos e privados.

Julga-se válido o enquadramento metodológico com base em pesquisas bibliográficas, visto que a discussão sobre a Logística Urbana de Cargas, no Brasil, ainda é inexpressiva quando comparada aos estudos de sistemas de transportes de pessoas, explorados, em sua maioria, pela Administração, Economia e Engenharia. Existe, portanto, uma lacuna na compreensão da temática que demanda a contribuição da Geografia; no entendimento do espaço urbano e de suas interações espaciais encontra-se a Logística Urbana, que produz e se reproduz através dos fluxos diversos pelo seu espaço.

A globalização aprofundou suas estratégias capazes de fomentar a competição global e de definir os agentes hegemônicos dessa corrida, sendo as grandes corporações também responsáveis pelo (re) ordenamento do território, bem como por impactos na política, na economia e na cultura da sociedade. Nesse contexto, a atuação do Poder Público e das empresas no território brasileiro tem se pautado cada vez mais na racionalidade e eficácia dos fluxos materiais e imateriais, de modo que a moderna logística surge como uma questão-chave para o desenvolvimento socioeconômico.

Assim, Silveira (2013) explica que a logística, tomada como foco em estudos de diversas áreas da ciência, é uma estratégia que, através do planejamento e da gestão 
especializada, interfere nos fixos e fluxos de transportes, de comunicação e no armazenamento. Responde também pela reestruturação econômica e espacial, capaz de ajudar a explicar a economia concernente à reorganização da rede urbana, à dinamização da relação intraurbana e às interferências nas diferenciações regionais.

Essas interações espaciais, qualificadas por Corrêa (1997) como "componente do espaço geográfico", um amplo e diverso deslocamento multidirecional de mercadorias, pessoas, capitais e informações, com diversas densidades de fluxos e velocidades mediante o transporte de cargas são amplamente determinantes para a produtividade do trabalho, o desenvolvimento socioeconômico e para a condução de um (re) ordenamento territorial mais justo no que se refere à acessibilidade e qualidade de vida.

Diante da acentuação dos fluxos e das respectivas relações estabelecidas nesse espaço, em razão dos intensos processos que ocorrem atualmente na produção e no consumo, consequências são perceptíveis na dinâmica da mobilidade urbana. Nesse contexto, a logística é fator fundamental, porém, vem sendo relegada ao segundo plano nas discussões e intervenções de planejamento e ordenamento territorial das cidades brasileiras.

Com o crescimento da movimentação de mercadorias, as relações comerciais foram intensificadas e aprofundadas nos centros urbanos brasileiros, estando diretamente ligadas ao cotidiano das pessoas, com o aumento dos congestionamentos nas regiões centrais. Esse problema atinge tanto a empresa fornecedora, que tem sua eficiência reduzida, quanto o morador da cidade, cuja qualidade de vida é afetada pelos diferentes tipos de poluição e pelas interferências dos caminhões e veículos de carga e descarga. Além disso, também há prejuízos para o Poder Público, que tem grande dificuldade em regulamentar e minimizar os impactos desse processo sem prejudicar a continuidade das atividades econômicas da área.

\section{UMA PROPOSTA DE PERIODIZAÇÃO E EVOLUÇÃO DA LOGÍSTICA}

A Logística tem apresentado uma contínua evolução na morfologia urbana e no seu conceito funcional. Ao longo do seu desenvolvimento chegou a ser considerada, junto ao Marketing $^{1}$, um dos principais pontos estratégicos do sistema de produção integrado, incorporando inovações e gerando outras de acordo com o atual conceito de Gerenciamento de Cadeia de Suprimentos.

\footnotetext{
${ }^{1}$ Marketing é a atividade, conjunto de instituições e processos para criar, comunicar, entregar e trocar ofertas que tenham valor para os clientes, parceiros e sociedade em geral. (American Marketing Association, 2013). 
O termo Logística, utilizado em diversas situações e de diferentes formas, teve suas origens principalmente em decorrência da Segunda Guerra Mundial. A etimologia da palavra revela sua natureza militar, posto que o étimo logis em francês signifique 'alojamento' e loger, 'alojar, aquartelar, abarracar'. Entretanto, outros etimólogos veem no conceito uma extensão do original, ou seja, o sentido numérico dos cálculos, estimativas, estatísticas e antevisões quantitativas que a técnica militar requeria quando sua função estava intimamente ligada à movimentação de tropas e suprimentos (MIRADOR, 1987, p. 6983).

Com o final da Segunda Guerra Mundial, a partir dos avanços científicos e tecnológicos, a Logística, até então restrita aos campos militares, passou a ser adaptada e compreendida pelas empresas, que a incorporaram gradualmente e acabaram por efetivá-la como um elemento de base, e não de apoio, das corporações que constituíam os circuitos espaciais produtivos.

Assim, encontramos atualmente inúmeras definições do conceito de Logística, mas todas estão baseadas em estudos comuns da Administração, Economia e das Engenharias. A seguir, apresentamos algumas delas.

Para Kobayashi (2000, p. 18),

A logística é considerada como um "sistema de distribuição física"; todavia esta deve ocupar-se não somente de bens materiais, mas também de serviços. Além disso, é necessário que a logística seja concebida como uma atividade de suporte em todos os campos para incrementar e solidificar o faturamento e as quotas de mercado das empresas.

Contudo, defendemos que o conceito não pode se limitar ao ponto de vista corporativo no âmbito das Ciências Exatas. Muito além disso, deve contemplar a materialidade e imaterialidade do uso, as racionalidades e irracionalidades, normas e gestão do território, aspectos que deverão ser mais bem abordados pela Geografia e ciências afins.

Segundo Castillo (2004, p. 83), podemos compreendê-la como:

O conjunto de processos, procedimentos e ações que visa organizar e otimizar o movimento de produtos, desde o fornecimento de insumos até o consumo final. Implica no acompanhamento do produto em seu movimento, gerenciamento de estoques, just-in-time/just-in-place, importação/exportação e outros serviços vinculados ao armazenamento, distribuição e agregação de valor aos fluxos materiais (certificação, embalagem, etiquetagem etc.). 
Assim, concordamos que a Logística é a sinergia de core competences ${ }^{2}$ infraestruturais (vias, modais, veículos, terminais, entrepostos, centros de produção e distribuição), estratégicas (conhecimentos e projeções científicas e empíricas), normativas (legislações, contratos e parcerias) e solidárias (cooperação) que conferirão valor, fluidez, competição e economia ao processo produtivo, desde a extração da matéria-prima até o consumo do produto final, e também no seu processo reverso.

Embora a Logística tenha ganhado forma no Brasil a partir da década de 1990, conforme veremos a seguir ela se fundamentou em uma estrutura relativamente estreita, com basicamente quatro pilares: Distância, Qualidade, Tempo e Informação, como ilustra a Figura 1:

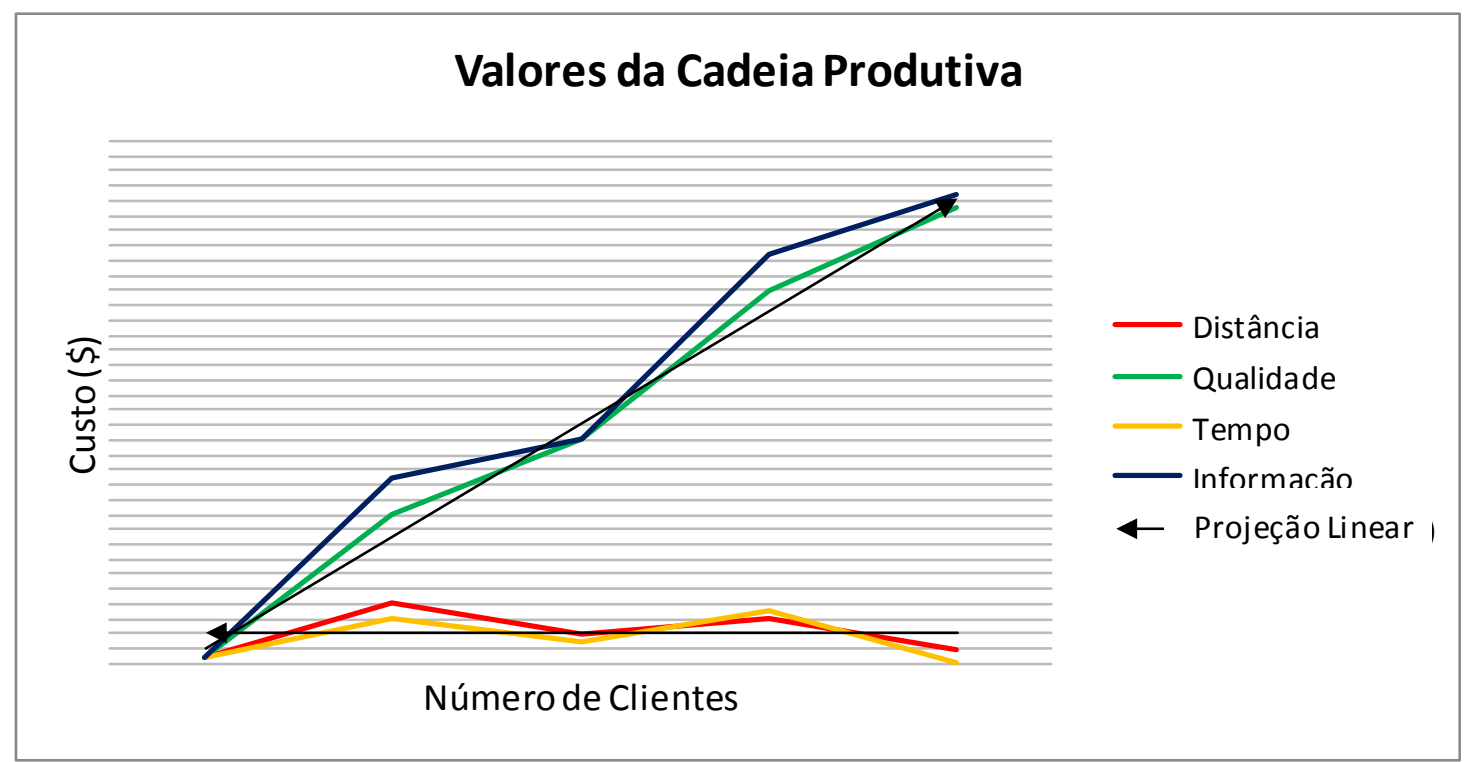

Figura 1 - Valores da Cadeia Produtiva. Fonte: Silva, 2016.

Tomando o caso do Brasil, em meados de 1960, com a intensificação dos processos de industrialização e urbanização, houve migrações rurais em direção à cidade, para a periferia e subúrbios circundantes. A necessidade de servir uma maior área urbana e manter maiores estoques fundou os valores da Logística no Brasil.

Conforme vimos na Figura 1, nos sistemas produtivos um dos elementos básicos é a distância espacial entre a indústria e os mercados consumidores: num extremo, a distância entre a fábrica e as matérias-primas; noutro, os artifícios necessários para a produção das mercadorias, tais como mão de obra, suplementos, adornos, materiais e

\footnotetext{
${ }^{2}$ Hamel e Prahalad (1995, p. 229) definem competências essenciais (core competence) como "um conjunto de habilidades e tecnologias que permite a uma empresa oferecer um determinado benefício aos clientes".
} 
ferramentas. Assim, a mercadoria, ao chegar no destino final satisfazendo o desejo do cliente, tem um valor agregado, que Novaes (2007) define como valor de lugar.

Devido à importância do deslocamento da mercadoria e de sua alocação no destino, outros dois elementos relevantes são a qualidade e o tempo, que devem ser considerados no valor final. Como exemplo, citamos os dabbawalas ${ }^{3}$, que têm sido objeto de estudo sobre o meio logístico, não apenas por sua eficiência na entrega de marmitas na Índia, mas também por sua capacidade administrativa, sem o auxílio de qualquer tecnologia, conforme ilustra a figura a seguir:

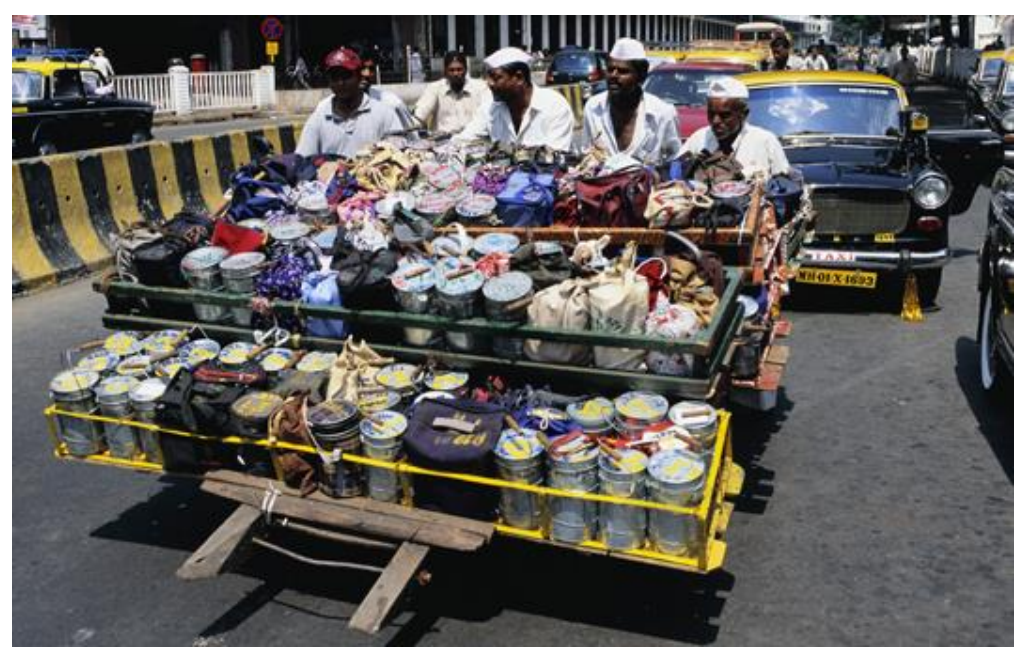

Figura 1 - Dabbawalas de Mumbai, Indía. Fonte: Revista Indian Online Seller, 2015.

No início da manhã, os dabbawalas retiram cerca de 200.000 refeições prontas da casa de seus clientes. O destino são milhares de escritórios localizados na área comercial, no lado oposto da cidade. Há um preciso limite de tempo para que o trabalho dos dabbawalas seja finalizado - o horário do almoço desses 200000 trabalhadores indianos. Durante a coleta nos bairros residenciais, os dabbawalas se valem de bicicletas, carrinhos de mão ou caixas de madeira que comportam até sessenta marmitas. Das casas, seguem para as estações de trem, onde outros integrantes dessa rede logística organizam sua distribuição de acordo com o destino das refeições. No desembarque, na área comercial da cidade, um novo grupo se encarrega de entregar em mãos o almoço caseiro nos escritórios. Uma hora depois começa a jornada reversa e todas as marmitas são devolvidas a seus locais de origem (EXAME, 2008).

Esse serviço é realizado com planejamento eficaz, dentro do prazo estabelecido, na maioria das vezes, pelo cliente e, ainda, com qualidade, isto é, com a comida em

\footnotetext{
3 A tradução literal de dabbawala é "pessoa que carrega caixa". O início da palavra, dabba, significa caixa neste caso as caixas são as marmitas-. wala é o sufixo para executor, em outras palavras, é a pessoa que executa alguma ação com a caixa. (THE ECONOMIST, 2008).
} 
temperatura adequada, apropriadamente embalada e em condições saudáveis para consumo.

Há também um último elemento que tem ganhado destaque e foi muito aproveitado pelas atividades logísticas: a informação, que vai desde a inserção de códigos de barra e rastreamento até à customização de rótulos individuais para cada tipo de consumidor. Com isso, embora seja agregado o valor da informação ao valor final, a empresa tende a fidelizar os clientes contra os seus concorrentes, já que soma valores positivos em sua cadeia produtiva.

Diante dessas colocações, já fica sabido que o Brasil ocupa a posição de subdesenvolvido no mundo. $\mathrm{O}$ tamanho e a desigualdade da distribuição de densidades técnicas, normativas e demográficas fizeram do território brasileiro um exemplo complexo de hierarquias da mobilidade - da Logística, tomada como condição de disputas territoriais.

Uma proposta de evolução apresenta as inovações e conjuntos técnicos que foram capazes de amplificar a circulação e comunicação. Atendendo aos avanços técnicocientífico-informacionais do sistema de produção, a Logística teve o seu processo de desenvolvimento divido por Novaes (2007) em quatro fases: Atuação Segmentada, Integração Rígida, Integração Flexível e Integração Estratégica (Figura 3).

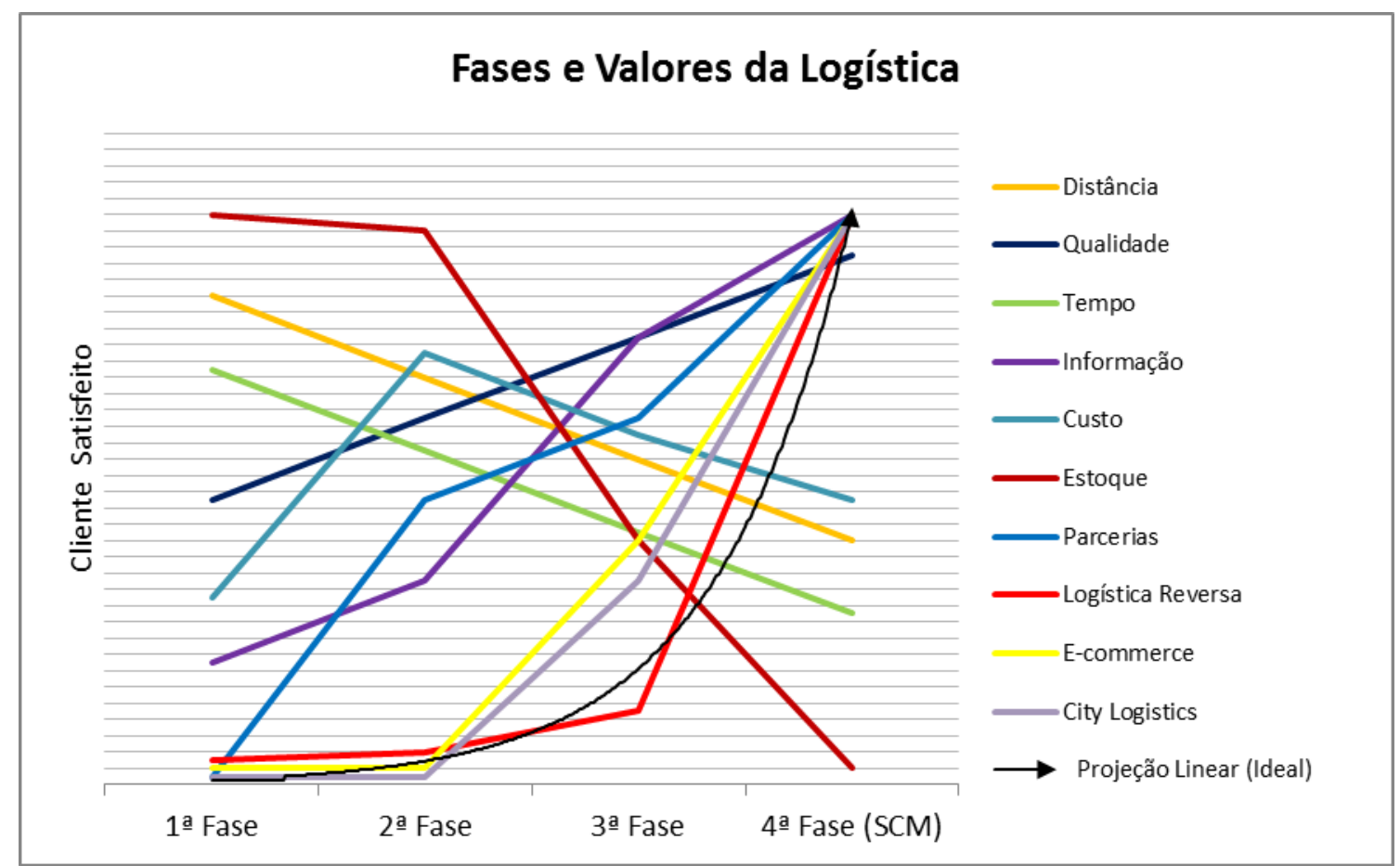

Figura 3 - Fases e Valores da Logística. Fonte: Silva, 2016. 
$\mathrm{Na}$ primeira fase (Atuação Segmentada), as empresas tinham pouco interesse no estoque e suas ações eram voltadas para as economias que poderiam ter se utilizassem modais de transporte mais baratos e com maior capacidade, interessando-lhes transportadoras que realizassem o serviço com o menor frete possível. Cada empresa tinha sua visão corporativa de como reduzir custos, ainda que o serviço prestado fosse precário. Tal perspectiva, até hoje, não é difícil de encontrar.

Em uma segunda fase, da Integração Rígida, com a inserção de produtos especiais, customizados e diferenciados quanto ao tamanho, material, cor, design, textura entre outros aspectos, as poucas opções de mercadorias disponíveis, agora, ofereciam um leque ampliado de tipos, concomitantes à incorporação de novos hábitos alimentares e de produtos supérfluos à necessidade da sociedade.

Devido ao êxodo rural, ao aumento da frota de veículos, à crise do petróleo no início da década de 1970 e às consequentes restrições de movimentação de veículos de carga no tráfego intraurbano, os movimentos logísticos que envolviam produção, custos de transferência e distribuição cresceram subitamente. Como resultado, houve maiores custos de transporte, mão de obra, matéria-prima, entre outros recursos, colaborando para a elevação das despesas logísticos totais. Foi quando se iniciou o desenvolvimento de novas alternativas de transporte, culminando na multimodalidade. Usos combinados de trens, navios, caminhões e até aviões começaram a ser intensificados, visando a redução de custos e o aproveitamento dos modais.

A terceira fase da Logística (Integração Flexível) é marcada pela introdução eletrônica de dados, pela integração nos níveis intraempresariais e por inter-relações dos fornecedores com os clientes. O avanço da telecomunicação e da informática possibilitou uma integração flexível no acompanhamento de estoques e vendas, com a inserção do código de barras, acelerando processos que antes eram realizados manualmente e demandavam muito tempo. Nessa fase tem-se uma preocupação com os desejos do cliente e a busca permanente por uma produção just-in-time e do "estoque zero".

Ainda segundo Novaes, é na quarta fase (Integração Estratégica), conhecida pelo conceito de Supply Chain Managment (SCM), que ocorre um salto qualitativo na concepção de Logística. As empresas passam a tratá-la como estratégia para garantir competitividades e induzir novos negócios. Diferente das três etapas antecessoras, nas quais a integração se dava basicamente em termos físicos e operacionais, agora a Logística consiste na troca de informações confidenciais, promovendo parcerias e investimentos. É o elemento 
diferencial do mercado globalizado, onde as disputas e a concorrência são cada vez mais acirradas.

Também são importantes marcos dessa fase modelos como o postponement ${ }^{4}$, que consiste numa espécie de produção de mercadoria/acessórios durante o transporte do próprio produto para o seu cliente, e o agile enterprises ${ }^{5}$, que são fábricas de mercadorias de alto valor agregado, geralmente eletrônicos, localizadas junto a aeroportos, atendendo com agilidade os pedidos feitos pelo e-commerce. Recente e tardiamente no Brasil, tem-se acrescentado a essa fase a crescente preocupação com a mobilidade sustentável e com a Logística Reversa, que hoje é tema de discussões mundiais.

Corrobora Novaes (2007), que pressupõe as quatro fases já explanadas, Christopher (1992) entende a SCM como uma rede de organizações, tecida nos dois sentidos, dos diferentes processos e atividades que produzem valor na forma de produtos e serviços colocados à disposição do consumidor final.

No entanto, cabe ressaltar os trabalhos de Lummus et al. (2001) e de Ross (1998), para quem a Logística está geralmente associada às corporações empresariais, ainda que realize conexões fornecedores-empresa e empresa-consumidor. Nessa percepção, a Logística é componente de um corpo maior, a SCM, que assume todos os fluxos desde o fornecedor até o consumidor.

Já o trabalho de Metz (1998) adota a progressão lógica do desenvolvimento da Logística:

\begin{abstract}
Integrated Supply Chain Management (ISCM) is a process-oriented, integrated approach to procuring, producing, and delivering products and services to customers. ISCM has a broad scope that includes sub-suppliers, suppliers, internal operations, trade customers, retail customers, and end users (METZ, 1998, p. 12). ${ }^{6}$
\end{abstract}

Diante da dualidade de perspectivas e da integração tecnológica e informacional que intencionalmente se alastra pelo mundo, sob a égide de grandes corporações que já tinham como base operacional a Logística, trataremos esse descompasso entendendo que para

\footnotetext{
${ }^{4} \mathrm{O}$ postponement consiste na fabricação de um produto base ou padrão em quantidades suficientes para realizar economia de escala, enquanto as características de finalização são adiadas até que os pedidos dos consumidores sejam recebidos (BOWERSOX; CLOSS, 1996). O termo postponement não será traduzido para o português neste trabalho, pois sua tradução literal não abrange toda a amplitude do termo em inglês.

5 Também chamadas de "empresas virtuais", no jargão da Logística (NOVAES, 2007).

${ }^{6}$ Supply Chain Gestão Integrada (SCM) é uma abordagem orientada a processos, integrada para aquisição, produção e fornecimento de produtos e serviços aos clientes. SCM tem um amplo escopo que inclui fornecedores, sub-fornecedores, operações internas, clientes comerciais, clientes de varejo e usuários finais (METZ, 1998, p. 12).
} 
atuar segundo os modernos conceitos e práticas da $S C M$ é necessário nos remeter à evolução da Cadeia Produtiva, até atingir o estágio de Gestão da Cadeia de Suprimentos.

Consideremos a SCM como uma integração entre os estágios logísticos cujos agentes atuam simultânea e estrategicamente, do o fornecedor ao consumidor, gerando produtos e serviços em menos tempo, menores distâncias e custos possíveis e com melhor qualidade para o cliente, que é a essência das interações e dos circuitos espaciais produtivos. Corrêa (1997) qualifica tais interações como "amplo e diverso deslocamento multidirecional com diferentes intensidades de fluxos e velocidades", a partir das quais o cenário urbano do transporte de cargas passou a sofrer com o caos de congestionamento, imobilidade, inacessibilidade, estrutura viária inadequada, equipamentos urbanos sucateados, falha de comunicação, entre outros empecilhos.

\section{A LOGÍSTICA URBANA DE CARGAS}

A urbanização tem sido um dos processos mais dominantes de boa parte da população mundial. No Brasil, 84,36\% (IBGE, 2010) dos habitantes, vivem em cidades. Considerando essa tendência, as questões sobre a Logística são de grande importância para apoiar as exigências de mobilidade de pessoas, mas também de bens e mercadorias nos grandes centros urbanos brasileiros.

Tradicionalmente, o foco do planejamento em transportes centrou-se nos passageiros, posto que a cidade ainda fosse vista apenas como local de interação humana, com padrões de vida ligados a relações comerciais e de lazer. No entanto, a cidade também é reconhecida por sua capacidade de produção, consumo e distribuição, isto é, por atividades ligadas à Logística Urbana.

Os crescentes fluxos de bens e mercadorias têm sido componentes fundamentais das mudanças nos sistemas econômicos em escalas globais, regionais e também locais. Esse cenário traz luz à Geografia Urbana, que nos últimos anos vem demandando estudos no segmento da Logística Urbana, a qual traz consequências diretas para as cidades, uma vez que se utiliza da infraestrutura, dos fluxos e das interações, potencializando os problemas já existentes.

Nas últimas décadas, as iniciativas e estratégias de várias grandes áreas da Ciência, integradas pela cooperação no planejamento urbano, culminaram no conceito de City 
Logistcs $^{7}$. O termo surgiu de forma pioneira na Dinamarca, em meados de 1990 (FRANÇA; RUBIN, 2005), como uma "raiz" da Logística Urbana que aprofundaria suas ações para muito além do transporte de cargas, orientando todos os aspectos produtivo-econômicos, sociopolíticos e ambientais do transporte de cargas da cidade, em uma visão holística de mobilidade urbana, considerando os custos e benefícios tanto do setor público quanto do privado.

O Conceito de City Logistics remete ao conjunto de iniciativas práticas implantadas com o objetivo de minimizar as problemáticas da Logística Urbana (no que se refere aos sistemas de transportes, operações de cargas e descargas, emissões de poluentes, etc.), considerando o caráter sistêmico da cidade. Assim a City Logistics enquanto um modelo de cidade consiste na orientação para as ações de Logística Urbana. (VILELA et al., 2013).

Desde medidas de traffic calming ${ }^{8}$, passando por sistemas de cooperação de transporte de cargas, centros logísticos até vias subterrâneas para escoamento de mercadorias, as propostas têm caminhado cada vez mais no sentido de incorporar o conceito de City Logistics. Dessa maneira, Taniguchi et al. (2003) fundamentam três pilares nos quais todas as alternativas precisam estar pautadas: sustentabilidade, mobilidade e qualidade de vida (Figura 4).

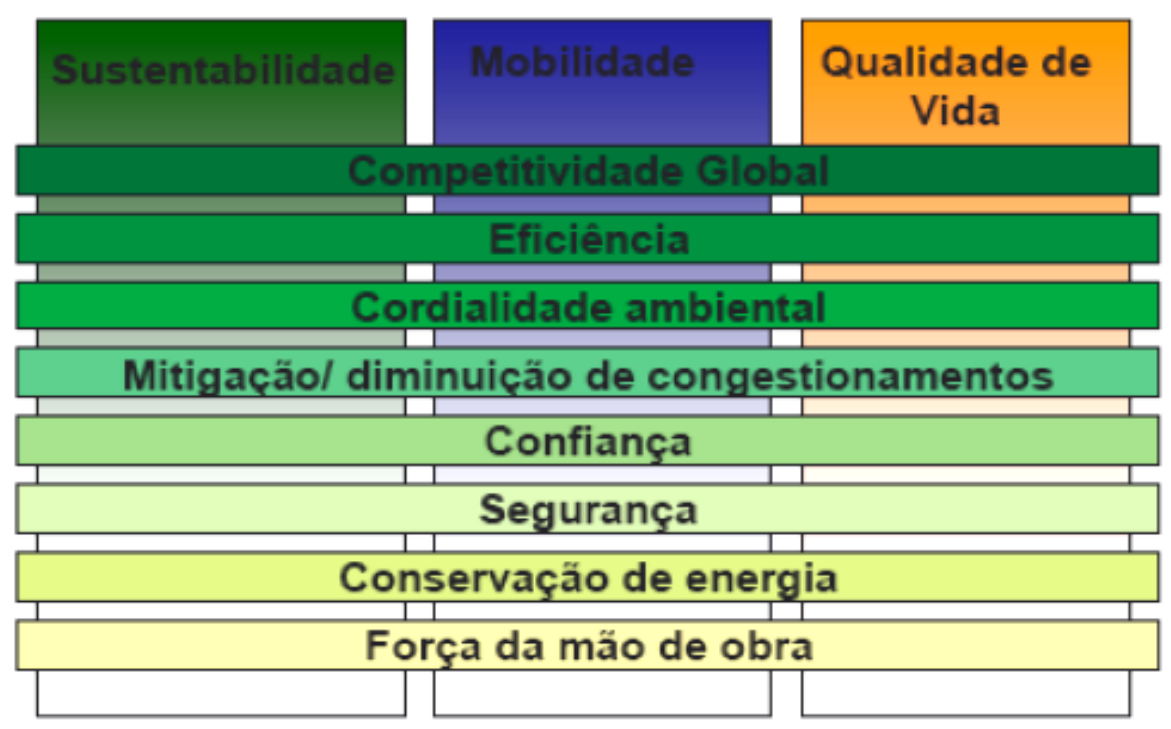

Figura 4 - Pilares da Logística Urbana. Fonte: Taniguchi et al., 2003.

\footnotetext{
7 Taniguchi et al. definem City Logistics como o processo para a completa otimização das atividades logísticas e de transportes pelas companhias públicas e privadas em áreas urbanas, considerando o aumento e o congestionamento do tráfego e o consumo de combustível dentro de uma estrutura de economia de mercado. (TANIGUCHI et. al, 2001).

${ }^{8}$ É o termo que designa a aplicação, através da engenharia de tráfego, de regulamentação e de medidas físicas, desenvolvidas para controlar a velocidade e induzir os motoristas a um modo de dirigir mais seguro e apropriado ao meio ambiente. (BHTRANS, 2013).
} 
Se por um lado os requisitos de tempo de ciclo foram substancialmente reduzidos entre 1960 e 1980, por outro, isso trouxe os crescentes custos logísticos, como aponta Rodrigue (2006). A partir de então, as principais realizações das empresas estiveram relacionadas aos ganhos de produtividade e distribuição. Nesse contexto, a conteinerização veio a conferir flexibilidade significativa e a expansão da infraestrutura clássica, como rodovias, terminais e aeroportos, também foi fundamental para o desenvolvimento da logística moderna.

Pode-se inferir que as mudanças nos padrões de consumo não são meramente quantitativas, mas também estruturais, porque envolvem sistemas produtivos, operacionais e, principalmente, distributivos. Portanto, o cerne da questão não reside na natureza, origem e destino dos movimentos da carga, mas em como esses fluxos estão se movendo no espaço. Isso nos leva ao domínio da Logística Urbana de Cargas, que abarca um vasto conjunto de atividades, desde a produção até o consumo de bens e mercadorias.

Assim, a Logística Urbana de Cargas apresenta-se como um esqueleto envolvido por questões de alta complexidade, com vieses políticos, sociais, infraestruturais, tecnológicos, institucionais e governamentais, cuja resolução é difícil, pois requer indispensavelmente uma integração entre os diversos agentes dos diferentes segmentos que compõem a sociedade.

$\mathrm{Na}$ perspectiva de racionalizar, otimizar, separar, organizar, desobstruir, transportar e circular, o Urbanismo Moderno parece ser a proposta de solução das cidades que enfrentam o caos. Para atingirem o patamar de City Logistcs as cidades brasileiras precisariam de ações direcionadas aos setores privados, mas principalmente aos setores públicos. Certamente, enfrentar-se-iam dificuldades de adaptação a esse novo cenário, justamente pelo costume com um padrão logístico que não privilegia a integração.

A Logística Urbana de Cargas tem uma dimensão geográfica abrangente, expressa em termos de fluxos, fixos e redes no espaço. Atividades que não foram tradicionalmente consideradas nas relações espaço-temporais, como a distribuição, agora estão sendo incorporadas e isso implica uma organização e sincronização dos fluxos através de nós e estratégias de rede, conforme ilustrado na Figura 5: 

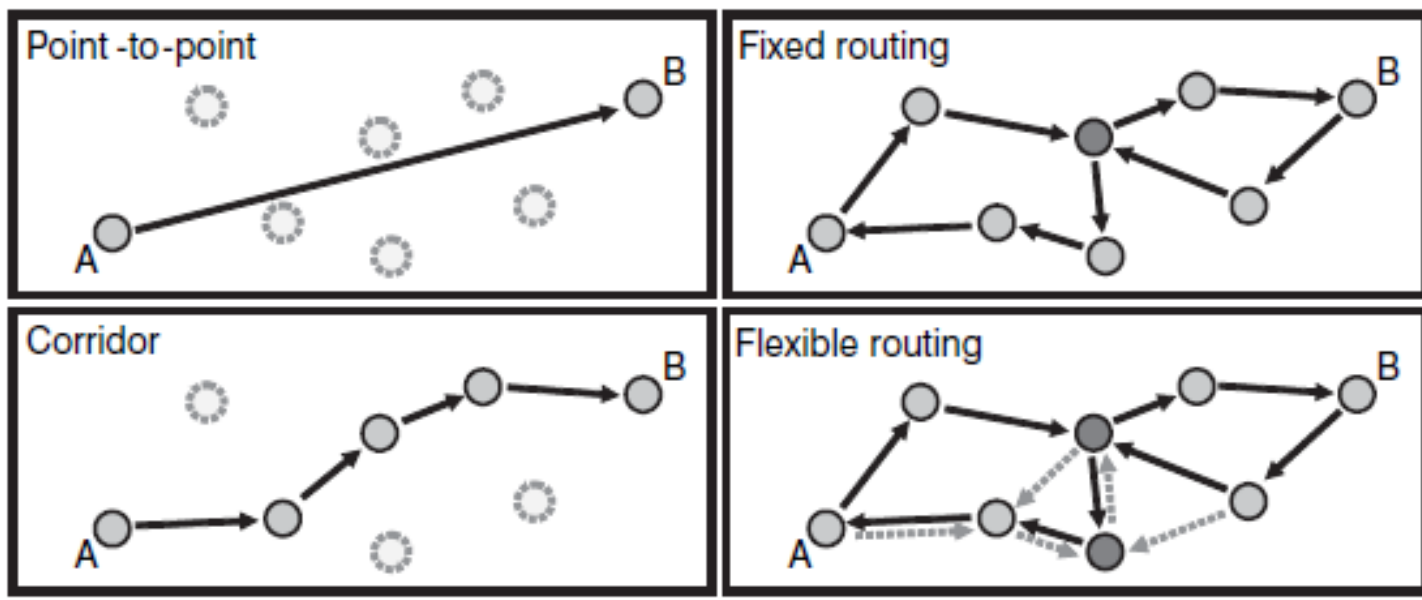

Flexible routing
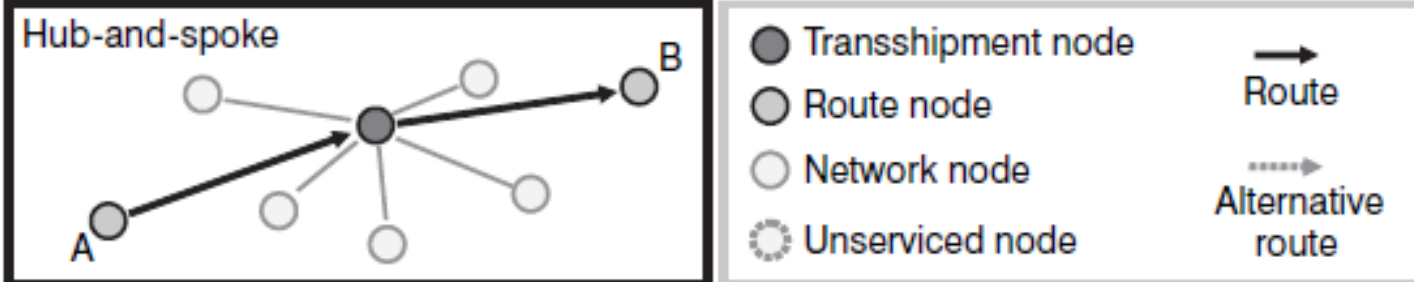

Figura 5 - Estratégias de Jean Paul Rodrigue na distribuição de cargas em redes. Fonte: Rodrigue, 2006.

Para Rodrigue (2006), temos quatro tipos de estratégias para a otimização da Logística de Cargas nos centros urbanos, sendo elas:

- Distribuição de Ponto-a-Ponto: é comum uma espacialização sem barreiras, em que o tempo é específico e as operações de carga ocorrem de maneira satisfatória. As exigências logísticas são mínimas.

- Corredores de Distribuição: muitas vezes ligam centros de alta densidade a terminais de distribuição; é um sistema alimentado por subcentros dispersos. Junto ao corredor, a mercadoria pode ser carregada ou descarregada nos centros de distribuição local/regional, atuando como terminais dentro do sistema distributivo.

- Rede Hub-and-Spoke: surgiu principalmente com a distribuição de cargas pelo modal aéreo e com centros de distribuição de alto rendimento, favorecidos por serviços de e-commerce, uma estrutura que só é possível se o bub tem a capacidade de lidar com grandes quantidades de cargas. Os requisitos logísticos são consequentemente grandes. Comumente, um grande núcleo distributivo está localizado em áreas centrais, onde terá acesso privilegiado aos terminais.

- Rede de Roteamento: tende a usar a configuração circular, em que a carga pode ser transportada de uma rota para outra através de centros específicos. As redes pendulares são caracterizadas pelos serviços de transporte de contêineres. Já as 
redes flexíveis são complexas estratégias que requerem um alto nível de integração logística, como rotas e hubs, que mudam em decorrência das variações, previsíveis ou não, de uma demanda integrada de mercadorias.

Com essa visão sobre o espaço urbano e as necessidades de um mundo globalizado, cujo ritmo é frenético, a Logística aplicada ao Planejamento Urbano objetiva oportunizar à sociedade a melhor qualidade de vida possível, através de um processo contínuo de coleta, organização, distribuição, entrega e informação, a fim de coordenar meios e recursos visando à harmonia dos centros urbanos. A partir dos resultados oriundos desse processo, pode-se diagnosticar e viabilizar decisões seguras e eficientes para o território, uma vez que este é conhecido, propiciando uma racionalização dos recursos disponíveis. Igualmente, é possível estabelecer metas de curto, médio e longo prazo (com meios e instrumentos para atingi-las) que aperfeiçoem as especificidades de cada cidade.

Apesar de ter emergido tardiamente no Brasil, em comparação com outros países, a Logística desenvolveu uma estrutura capaz de alimentar os circuitos espaciais produtivos e, além disso, se tornou um elemento importante no reordenamento do território brasileiro, ocupando posições de destaque na composição dos orçamentos públicos e privados.

\section{CONSIDERAÇÕES FINAIS}

Conforme explanado nas seções anteriores, o advento da Logística no Brasil deu-se já no final do século XX. No entanto, somente nos primeiros anos do século XXI ela se inseriu como protagonista nos circuitos espaciais de produção, sendo pauta de estudos técnicos e científicos nas universidades e fator de estratégia das empresas e do Poder Público.

Progressivamente, o conceito de Logística Urbana de Cargas foi sendo absorvido e introduzido nas médias e grandes corporações privadas, a partir das suas especificidades e circunstâncias espaço-temporais, alcançando a ampliação de sua aplicação no Poder Público, através do setor de Planejamento Urbano. Durante a década de 1990, alguns países europeus (Holanda, Alemanha, Bélgica, Suíça e Dinamarca) deram início a projetos-piloto que referenciavam modelos alternativos para a distribuição de cargas nos centros urbanos, racionalizando tempo, espaço e recursos. Por conseguinte, as médias e grandes cidades do mundo começaram a buscar a harmonia entre a competitividade econômica e a 
sustentabilidade social frente à aplicação da Logística Urbana de Cargas no meio ambiente urbano.

A partir daí, a globalização e o neoliberalismo mercantil acabaram por aumentar fisicamente, em sua contradição, as distâncias entre a matéria-prima, a produção e o consumidor final. Dessa forma, tem-se um maior número de veículos operando em menos tempo, num uso intensivo do território. No caso brasileiro, nos cabe ressaltar, o modal rodoviário é o mais explorado.

Diante do exposto, temos um cenário atual extremamente dependente dos transportes. E quando discutimos a Logística Urbana de Cargas se torna evidente uma segmentada estrutura, que compreende empresas de consultoria logística, rastreamento e monitoramento de cargas, de carga expressa e até fabricantes de softwares e equipamentos. Embora algumas delas se tornem core competences e se consolidem no mercado a partir de uma influência regional exercida por seus aportes tecnológicos, essas empresas mantêm níveis baixos de operação de serviços, se comparadas às europeias.

Configura-se, assim, uma realidade marcada pela complexidade e pela alta competitividade nos serviços de distribuição, o que provoca graves problemas de acessibilidade ao espaço urbano e às suas atividades de trabalho, lazer, compras ou de outras naturezas. Dentre os prejuízos gerados estão a poluição sonora, os congestionamentos, os acidentes, o stress etc.

Logo, nota-se a importância de estudos que discutam a Logística Urbana de Cargas e apresentem alternativas para os sistemas de transporte e circulação, a fim de satisfazer as necessidades de mobilidade, desenvolvimento econômico e de bem-estar social.

Urge somar esforços para minimizar os problemas cada vez mais presentes nos centros urbanos, o que requer mudanças estruturais nas orientações socioeconômicas, perpassando uma política de transporte orientada pela economia até chegar a uma política integrada, orientada pela harmonia e pelo bem-estar da sociedade. A compatibilização entre desenvolvimento socioeconômico, acessibilidade e mobilidade exige que se detenha o crescimento do tráfego motorizado e se incentive o uso de meios de locomoção menos poluentes.

A dinâmica urbana, que é contínua, tem papel fundamental nesse processo, pois a urbanização e a descentralização são fenômenos estreitamente modulantes dos padrões de vida da sociedade, considerando que ambos não laboram sem o aumento da mobilidade. Sendo assim, na ausência de um planejamento quanto ao uso e ocupação do solo e ao direcionamento das atividades econômicas, a cidade tende à criação de ocupações 
dispersas, desencadeando aumento do perímetro urbano (ainda com extensos terrenos vazios), intensificação da distância no trajeto trabalho-casa, especulação imobiliária, incipiência do saneamento básico, insuficiência de transporte público e equipamentos urbanos, além da insegurança.

No intuito de sanar tais problemas, uma das práticas adotadas é o aprimoramento da Logística Urbana. Entretanto, para as corporações, tal estratégia acaba esbarrando nas políticas públicas nacionais e locais, já que o Poder Público pouco se empenha administrativamente para a melhoria desse cenário. A solução, então, para a harmonia entre ambos está no Planejamento Participativo em que se encontrem políticas públicas que integrem considerações ambientais e sustentáveis na tomada de decisões.

\section{REFERÊNCIAS}

CASTILLO, R. Transporte e logística de granéis sólidos agrícolas: componentes estruturais do novo sistema de movimentos do território brasileiro. Investigaciones Geográficas, Boletin del Instituto de Geografia, UNAM, México-DF, n. 55, 2004.

CHRISTOPHER, M. Logistics and Supply Chain Management. London: Pitman Publishing. 1992.

CORRÊA, R. L. Interações espaciais. In: CASTRO, I. E. de; GOMES, P. C da C.; CORRÊA, R. L. (Org.). Explorações geográficas. Rio de Janeiro: Bertrand Brasil, 1997, p. 279-318.

EXAME, Revista. Mais da metade dos Brasileiros está na classe média. Disponível em: < http://exame.abril.com.br/brasil/noticias/mais-da-metade-dos-brasileiros-estao-naclasse-media $>$. Acesso em: 10 mar. 2016.

FRANÇA, P. T.; RUBIN, M. Transporte Urbano de Mercadorias, Logística Urbana e City Logistics. Florianópolis: Grupo de Estudos Logísticos - GELOG/UFSC, 2005.

INSTITUTO BRASILEIRO DE GEOGRAFIA E ESTATÍSTICA (IBGE). Censo Demográfico de 2010. Rio de Janeiro: IBGE, 2011. Disponível em: $<\underline{\text { http://censo2010. }}$ ibge.gov.br/>. Acesso em: 05 fev. 2016.

KOBAYASHI, S. Renovação da logística: como definir estratégias logísticas de distribuição física global. São Paulo: Atlas, 2000.

LUMMUS, R. T. et al. The relationship of logistics to supply chain management: developing a common industry definition. Industrial Management \& Data Systems, Emerald, v. 108, n. 8, p. 426-431, 2001.

METZ, P. J. Demystifying Supply Chain Management. Supply Chain Management Review, Winter, $\quad$ p. 1-11, $1998 . \quad$ Disponível em 
< http://www.manufacturing.net/scl/archives/1998/04myst.htm>. Acesso em: 10 mar. 2016.

MIRADOR. Enciclopédia Internacional. São Paulo - Rio de Janeiro: Encyclopédia Brittannica do Brasil Publicações, 1987. p. 6982-6984.

NOVAES, A. G. Logística e gerenciamento da cadeia de distribuição: estratégia, operação e avaliação. 3. ed. Rio de Janeiro: Elsevier, 2007.

RODRIGUE, J-P. The Geography of Transport Systems. 3rd revised ed. New York, USA: Routledge, 2006.

ROSS, F. D. Competing through Supply Chain Management-creating marketwinning strategies through supply chain partnerships. USA: Chapman \& Hall, 1998.

SILVEIRA, M. R. Infraestruturas e Logística de Transportes no Processo de Integração Econômica e Territorial. Mercator, Fortaleza, v. 12, p. 41-53, 2013.

TANIGUCHI, E. et al. Transparências apresentadas no Congresso de City Logistcs em Madeira. Portugal, 2003.

VILELA, L. O. et al. Trasnporte Urbano de Cargas: reflexões à luz da Geografia dos Transportes. Observatorium: Revista Eletrônica de Geografia, Uberlândia, n. 14, p. 103-120, 2013. Disponível em: $<$ http://www.observatorium.ig.ufu.br/pdfs/5edic/n14/06.pdf $>$. Acesso em: 10 mar. 2016.

VILELA, L. O. Logística urbana na perspectiva da geografia dos transportes: abordagem e tratativa de problemas resultantes do transporte de cargas. 2013. $240 \mathrm{f}$. Tese (Doutorado em Geografia) - Instituto de Geografia, Universidade Federal de Uberlândia, Uberlândia, 2013. 